\title{
Venous thromboembolism in obese pregnant women: approach to diagnosis and management
}

\author{
Ann Kinga Malinowski ${ }^{1}$, Dorota Bomba-Opoń2 ${ }^{2}$ Jacqueline Parrish ${ }^{1}$, \\ Urszula Sarzyńska², Dan Farine ${ }^{1}$ \\ ${ }^{1}$ Department of Obstetrics \& Gynecology, Division of Maternal Fetal Medicine Mount Sinai Hospital, Toronto, Canada \\ ${ }^{2} 7^{\text {st }}$ Department of Gynecology \& Obstetrics, Medical University in Warsaw, Poland
}

\begin{abstract}
Venous thromboembolism (VTE) remains among the leading causes of maternal mortality in the developed world, presenting variably as deep vein thrombosis (DVT), pulmonary embolism (PE) or cerebral vein thrombosis (CVT), among others. Obesity in particular has been recognized as the principal contributing factor to the risk of VTE in pregnancy and with the global increase in the rates of obesity affecting reproductive age women, heightened awareness of the risk and consequences of VTE in this population are vital. Thus, prophylaxis, diagnosis and treatment of VTE in the obese gravida are discussed.

Key words: venous thromboembolism, deep vein thrombosis, pulmonary embolism, cerebral vein thrombosis, pregnancy, obesity, anticoagulation, low molecular weight heparin
\end{abstract}

\section{INTRODUCTION}

Venous thromboembolism (VTE) is a major cause of mortality in pregnant women in the developed world [1, 2], often presenting as deep vein thrombosis (DVT) or pulmonary embolism (PE), and more rarely as cerebral vein thrombosis (CVT). Obesity is a well-known risk factor for these potentially fatal complications, and has been linked with a higher likelihood of maternal death in the United Kingdom's Confidential Enquiries into Maternal Deaths and Morbidity [2]. Given the paucity of randomized-controlled trials in this field, most recommendations come from observational studies and expert opinion. With the increase in the rates of obesity in women of reproductive age in Poland, focused guidance is needed to support both parturients and practitioners throughout pregnancy and postnatally. As such, the current review, focuses on the role of obesity as a leading risk factor for VTE, and readers are directed to other published works for discussion of other VTE-related risk factors, including thrombophilia and history of prior events [3-5].

\section{EPIDEMIOLOGY}

The actual incidence of VTE in pregnancy is difficult to estimate, owing to its relative rarity, retrospective observations, variable risk factor profiles and inconsistent thromboprophylaxis. A reasonable and accepted incidence is about 1-2/1000 pregnancies [6]. A large-scale Scandinavian study conducted between 2001 and 2011, assessing the risk of VTE during 180 days postpartum, showed a cumulative incidence of 18.4/10,000 deliveries, compared to 4.7/10,000 in non-pregnant women; with the highest risk in the first week postpartum [7]. On the other hand, the absolute risk of antepartum VTE was recently estimated at 8-9/10,000 deliveries [8]. This finding is consistent with the literature, with estimates of the risk of VTE of 6 to 9 times higher during the third trimester, 84 fold higher in the first 2-6 weeks postpartum, and up to 60 fold higher in the first 3 months postpartum, as compared to the non-pregnant population [8]. This corresponds to the maternal pregnancy-related physiologic alterations of hemostatic parameters, with the peak of the pro-coagulant state in the third trimester 
and early postpartum period, potentiated by the inherent vascular damage sustained at time of delivery. Yet, while the VTE risk predominates during these time periods, the magnitude of risk in the first and second trimesters should not be underestimated [9], and may be heightened by the pro-coagulant states associated with early stages of pregnancy, such as hyperemesis gravidarum or ovarian hyperstimulation syndrome [10].

Obesity stands among the most frequent risk factors for VTE in the obstetric population, augmenting the risk arising from the pregnancy and puerperium themselves, with an adjusted odds ratio (OR) of 5.3 (95\% confidence interval [Cl] 2.1-13.5) [6]. Similarly, a BMI of $25-29.9 \mathrm{~kg} / \mathrm{m}^{2}$ (overweight) is considered a weaker, yet common risk factor for VTE [10]. Furthermore, an obese parturient is at a greater risk of a PE (adjusted OR 14.9, 95\% Cl 3.0-74.8) than DVT (adjusted OR 4.4, 95\% Cl 1.6-11.9) [11], the significance of which becomes apparent with the observation that $60 \%$ of women who died from PE in the UK between 2003 and 2008 were obese (body mass index [BMI] $30 \mathrm{~kg} / \mathrm{m}^{2}$ or higher), and almost every woman who died from VTE after vaginal delivery was obese and/or over 40 years old [10].

With Poland noted in 2014 to have one of the highest rates of obesity amongst countries within the European Union, with the contribution of overweight women 18 years or older cited at $46.7 \%$ [12], a comprehensive understanding of the prophylaxis, diagnosis, and management of VTE is paramount.

\section{PATHOGENESIS OF VTE}

The Virchow's triad (comprised of venous stasis, hypercoagulable blood, and vascular damage) as the inciting mechanism for development of VTE has been long-recognized [13]. The expected, physiologic alterations typical of pregnancy have the potential to affect all three of these elements. Venous stasis intensifies with advancing gestation through progesterone-mediated venodilation, venous compression of the pelvic veins by the gravid uterus and structurally-driven compression of the left iliac vein by the right iliac artery, at its crossover point [14]. This latter observation clarifies the predilection of VTE formation in the left lower extremity $[15,16]$. Additionally, a shift within the hemostatic parameters favouring hypercoagulability, induced in anticipation of peripartum blood loss; emulated by the increase of pro-coagulant factors (fibrinogen and factors $V$, IX, X and VIII), decrease in anticoagulant activity (diminished protein $\mathrm{S}$ and elevated activated protein $\mathrm{C}$ resistance) and reduction in fibrinolytic activity (increased plasminogen activator inhibitor type 1 and 2 and decreased tissue plasminogen activator), results in intensified thrombin generation and tempered clot dissolution [13]. The risk for VTE induced by the procoagulant state is further augmented in individu- als diagnosed with thrombophilia [17]. Finally, this risk is potentiated by the vascular disruption of pelvic vasculature sustained during vaginal delivery, and to a greater extent during operative delivery or Cesarean section [13].

Beyond these physiologic alterations, the domains of the Virchow's triad are further affected by obesity. The additional abdominal adiposity and persistently elevated intra-abdominal pressure further restrict venous return above the effects already exerted by the weight of the gravid uterus [15]. Challenges with ambulation and altered mobility may result in relative inactivity, further hindering venous return and potentiating VTE risk [15].

Finally, the high metabolic activity of adipose tissue, resulting in the liberation of substances including interleukin-6, plasminogen activator inhibitor-1 and tumor necrosis factor- $\alpha$ (TNF- $\alpha)$, tissue factor, and (PAI-1), generates a hypofibrinolytic, prothrombotic, proinflammatory, environment, heightens endothelial dysfunction and promotes oxidative stress. This cascade in turn further exacerbates the risk of a VTE [18-20].

\section{PREVENTION OF VTE IN OBESE PREGNANT WOMEN}

Based on existing practice guidelines pharmacologic thromboprophylaxis is suggested once the estimated VTE risk is thought to surpass $1 \%$ [16]. Whereas antenatal thromboprophylaxis is not indicated solely for high BMI, the potentiation of risk in the presence of co-existing risk factors predisposing to VTE cannot be underestimated (Table 1) $[10,16,21]$.

For patients with clinical or laboratory suspicion of an increased bleeding risk, the benefits and hazards of bleeding and thrombosis must be considered and management decisions should be made following discussion with the treating haematologist, with acquired expertise in the treatment of such disorders in pregnancy. Proposed prophylactic doses of low molecular weight heparin (LMWH) according to weight are presented in Table 2 .

\section{CLINICAL MANIFESTATIONS OF VTE}

Heightened attentiveness to the signs and symptoms of VTE is crucial for prompt assessment and treatment and in order to decrease the risk of mortality [22]. Yet this intent is frustrated by the similarities between the classic symptoms of VTE (notably edema of the affected extremity, tachycardia, tachypnea, and dyspnea), and common symptoms frequently disclosed during the course of uncomplicated pregnancy, but often more frequently reported by the obese pregnant patient, sometimes leading to diagnostic delays [22-24].

Unilateral leg pain and swelling (especially of the left lower extremity) are more indicative of DVT, particularly if associated with local discomfort and warmth, or a degree 
Table 1. Risk assessment for VTE prophylaxis (RCOG) [10]

\begin{tabular}{|c|c|}
\hline Risk factor & Score \\
\hline \multicolumn{2}{|l|}{ Pre-existing risk factors } \\
\hline Previous VTE except a single event related to major surgery & 4 \\
\hline Previous VTE provoked by major surgery & 3 \\
\hline Known high-risk thrombophilia & 3 \\
\hline $\begin{array}{l}\text { Medical comorbidities, e.g. cancer, heart failure; active systemic lupus erythematosus, inflammatory polyarthropathy or } \\
\text { inflammatory bowel disease; nephrotic syndrome; type I diabetes mellitus with nephropathy; sickle cell disease; current } \\
\text { intravenous drug use not user }\end{array}$ & 3 \\
\hline Family history of unprovoked or estrogen-related VTE in first-degree relative & 1 \\
\hline Known low-risk thrombophilia (no VTE) & 1 \\
\hline III degree obesity $-\mathrm{BMI}=40$ or more & 2 \\
\hline II degree obesity $-\mathrm{BMI}=30$ or more & 1 \\
\hline Gross varicose veins & 1 \\
\hline Parity $\geq 3$ & 1 \\
\hline Smoker & 1 \\
\hline Age $>35$ years & 1 \\
\hline \multicolumn{2}{|l|}{ Obstetric risk factors } \\
\hline Pre-eclampsia in current pregnancy & 1 \\
\hline ART/IVF (antenatal only) & 1 \\
\hline Multiple pregnancy & 1 \\
\hline Caesarean section in labour & 2 \\
\hline Elective caesarean section & 1 \\
\hline Mid-cavity or rotational operative delivery & 1 \\
\hline Prolonged labour ( $>24$ hours) & 1 \\
\hline PPH (> 1 litre or transfusion) & 1 \\
\hline Preterm birth $<37$ weeks in current pregnancy & 1 \\
\hline Stillbirth in current pregnancy & 1 \\
\hline \multicolumn{2}{|l|}{ Transient risk factors } \\
\hline $\begin{array}{l}\text { Any surgical procedure in pregnancy or puerperium except immediate repair of the perineum, e.g. appendicectomy, postpartum } \\
\text { sterilisation }\end{array}$ & 3 \\
\hline Hyperemesis & 3 \\
\hline OHSS (first trimester only) & 4 \\
\hline Current systemic infection & 1 \\
\hline Immobility, dehydration & 1 \\
\hline $\begin{array}{c}\text { RECOMMENDATIONS: } \\
\text { Total score: } \\
\geq 4 \text { antenatally, consider thromboprophylaxis from the first trimester } \\
3 \text { antenatally, consider thromboprophylaxis from } 28 \text { week } \\
\geq 2 \text { postnatally, consider thromboprophylaxis for at least } 10 \text { days }\end{array}$ & \\
\hline
\end{tabular}

of leukocytosis beyond what would be expected for pregnancy alone $[22,25]$. Additional relevant elements, such as immobilization, unequal calf-size differing by $>3 \mathrm{~cm}$ (measured $10 \mathrm{~cm}$ below the tibial tuberosity), or unilateral swelling affecting the entire extremity warrant in-depth assessment [26]. Similarly, less typical presentation consisting of abdominal discomfort, or reports of pain solely in the flank, buttocks, or groin are suspicious in women with an increased risk of VTE and clarification of their etiology should be pursued, as they may be indicative on an iliac vein thrombosis, the risk of which is increased in pregnancy [27].

PE most commonly presents with dyspnea and pleuritic chest pain, although it can also be associated with cough, hematemesis, or syncope $[26,28]$. Although more rarely, increased jugular venous pressure and cardiovascular collapse have also been documented [26]. These symptoms may be seen in absence of or in association with the symptoms of DVT [26]. Barring absolute contraindications, 
Table 2. Weight-based dosing of LMWH

\begin{tabular}{|c|c|c|c|c|}
\hline \multirow{2}{*}{ Indication } & \multirow{2}{*}{ Weight [kg] } & \multicolumn{3}{|c|}{ Agent (administered subcutaneously) } \\
\hline & & Enoxaparin [mg] & Dalteparin [units] & Nadroparin [units] \\
\hline \multirow{5}{*}{ Prophylactic } & $<50$ & $20 \mathrm{mg}$ daily & 2,500 units daily & 1,900 units daily \\
\hline & $50-90$ & 40 mg daily & 5,000 units daily & $\begin{array}{l}2,850 \text { units daily }(<70 \mathrm{~kg}) \\
3,800 \text { units daily }(>70 \mathrm{~kg})\end{array}$ \\
\hline & $91-130$ & 60 mg daily & 7,500 units daily & 38 units/kg daily \\
\hline & $131-170$ & 80 mg daily & 10,000 units daily & 38 units/kg daily \\
\hline & $>170$ & $0.6 \mathrm{mg} / \mathrm{kg}$ & 75 units/kg daily & 38 units/kg daily \\
\hline Therapeutic & & $\begin{array}{l}1 \mathrm{mg} / \mathrm{kg} \text { bid or } \\
1.5 \mathrm{mg} / \mathrm{kg} \text { daily }\end{array}$ & $\begin{array}{l}200 \text { units/kg daily or } \\
100 \text { units/kg bid }\end{array}$ & 86 units $/ \mathrm{kg}$ bid \\
\hline
\end{tabular}

if required investigations cannot be completed expeditiously, weight-based, therapeutic anticoagulation ought to be commenced pending test completion [14].

\section{Diagnostic modalities}

The routine approach to VTE assessment requires modification in pregnancy, given that existing prediction rules have been extrapolated from studies on non-pregnant individuals and have not undergone validation in pregnancy $[14,16]$. Existing guidelines discourage their use or the sole dependence on negative $\mathrm{d}$-dimer results to rule out VTE in pregnancy [16], and encourage objective investigations including imaging.

\section{Deep vein thrombosis}

Compression ultrasound (CUS) of the venous system is the principal imaging modality for investigation of DVT during pregnancy, as it is non-invasive and allows for avoidance of radiation exposure $[27,29]$. Targeted examination extending from the iliac vein to the popliteal vein, incorporating Doppler interrogation of iliac vein flow (normally non-compressible) is crucial in view of the risk of iliac vein DVT in pregnancy $[16,22,24,30]$. Whereas a negative CUS has a negative predictive value of $98.9 \%$ (95\% Cl 95.5-99.8) during pregnancy and postpartum, a repeat CUS within one-week is suggested by most current guidelines [16, 29]. Where obstruction of the iliac vein is suspected by the absence of flow, an MRI may be indicated to further clarify the diagnosis [16].

\section{Pulmonary embolism (PE)}

In individuals presenting with respiratory symptoms suggestive of a PE, investigation for a DVT is still warranted $[16,27,31]$. Should a DVT be identified, weight-based therapeutic anticoagulation is required as for a $\mathrm{PE}$, thus further imaging for a PE may be unnecessary, avoiding its inherent radiation exposure $[27,31]$. Should DVT imaging be negative or unavailable, a ventilation/perfusion (V/Q) scan or computer tomographic pulmonary angiography (CT-PA) is indicated for the diagnosis of PE [16, 31]. While the reported fetal radiation dose associated with a CT-PA is 0.01 milliGray ( $m G y)$, the fetal radiation dose associated with the perfusion part of the V/Q scan is $0.12 \mathrm{mGy}$; correlating with projections of fatal malignancy to 15 years of age of $<1 / 1,000,000$ and $1 / 280,000$, respectively [32]. Whereas this may render the CT-PA a better modality form the fetal perspective, it should be noted that the degree of fetal radiation for both CT-PA and the perfusion portion of the V/Q scan are well below the safety thresholds, lack teratogenic associations, and reflect extremely low absolute risks [33]. Conversely, CT-PA delivers $10 \mathrm{mGy}$ of radiation to the maternal breast in contrast to the perfusion part of a V/Q scan which delivers $0.28 \mathrm{mGy}$; a dose 40 times higher at a sensitive time of rapid breast tissue proliferation, potentially increasing the lifetime risk of breast cancer $[27,31]$.

\section{Cerebral vein thrombosis}

The incidence of cerebral vein thrombosis (CVT) is much lower than DVT and PE, and has been reported to occur in $0.01-0.04 \%$ of pregnancies [16]. BMI $>30 \mathrm{~kg} / \mathrm{m}^{2}$ increases the risk of CVT (adjusted OR 3.50; 95\% Cl 2.00-6.14), while hormonal contraception exacerbates this risk further (adjusted OR 29.26; 95\% Cl 13.47-63.60) [34]. Pregnancy, the third trimester and postpartum period in particular, has also been associated with an increased risk of CVT [35]. Typical symptoms consist of generalized, progressively worsening headache, and at times "thunderclap" headache [36]. This may be accompanied by diplopia and papilledema, owing to sixth nerve palsy [35]. Convulsions, abnormal mentation, and focal deficits may also be present [37]. It is important to appreciate that $\mathrm{CT}$ without contrast will often be normal inspite of a CVT [35]. Time-of-flight magnetic resonance venography (TOF MRV) is the preferred imaging technique for diagnosis, especially antenatally [38]. Following diagnosis, therapeutic anticoagulation, detailed below, as for any form of VTE should be commenced [16]. 


\section{MANAGEMENT OF ACUTE VTE Choice of treatment agent}

LMWH is the preferred agent for treatment of VTE during pregnancy, whereas unfractionated heparin (UFH) is an alternate choice should LMWH be unavailable or contraindicated [16, 21, 31, 39]. Both LMWH and UFH potentiate the activity of antithrombin (including anti-factor-lla and anti-factor-Xa activity), reduce formation of thrombus, and enhance fibrinolysis [14]. Neither agent crosses the placenta $[40,41]$. A recent systematic review substantiated the safety and efficacy of LMWH for management of VTE in pregnancy, focusing on the reduced likelihood of bleeding, osteoporosis, and heparin-induced thrombocytopenia (HIT) in comparison to UFH [42-44]. No instances of HIT have been documented thus far with use of LMWH in pregnancy; nevertheless, it is worth mentioning that in cases of HIT or allergies to UFH/LMWH, heparanoids (i.e. fondaparinux or danaparoid), agents that lack cross-reactivity with HIT antibodies, may be considered during pregnancy following hematologic consultation $[42,45,46]$.

Vitamin $\mathrm{K}$ antagonists, such as warfarin, cross the placenta and are typically not indicated for management of VTE in pregnancy except in very unique circumstances, as they are associated with substantial fetal risks consisting of teratogenicity, fetal demise, and fetal hemorrhage [16, 21, 47-49]. Novel anticoagulation agents, such as oral direct thrombin inhibitors (i.e. dabigatran) and anti-Xa inhibitors (i.e. rivaroxaban, apixaban) are also to be avoided, given absence of pregnancy data $[16,21,39]$.

Finally, thrombolytic therapy (streptokinase, r-tPA, urokinase) should be considered carefully, given its associated risk of hemorrhagic complications, and only in instances of massive VTE associated with hemodynamic compromise or with a potential threat to life or $\operatorname{limb}[16,31,39,50,51]$. The use of vena cava filters should likewise be restricted to cases of acute VTE in the setting of imminent or threatened labour with contraindication to anticoagulation, or where substantial bleeding is encountered [16, 52-54].

\section{Anticoagulation dosage, duration, and peripartum management}

Dosing of therapeutic LMWH is weight-based (Table 2). Pregnancy-related physiologic adaptation resulting in amplification of maternal blood volume peaking in the third trimester at around 50\%, augmentation of glomerular filtration with higher renal excretion, and enhancement of protein-binding, alter the pharmacokinetic properties of LMWH and UFH [55]. Twice-daily dosing for maintenance of therapeutic levels has been proposed by some [16,31], while once-daily dosing is supported by others [55]. Similarly, the need for anti-FXa monitoring remains unclear [9, 16, 31].
All women receiving LWMH antenatally should be advised to withhold injections when bleeding is noticed or labour begins [10]. Prophylactic anticoagulation can be ceased with labour onset, or if delivery is planned, the last dose should be administered the day before the planned date $[15,16,31]$. Planned delivery is recommended for women on therapeutic anticoagulation $[15,16]$. In cases of VTE diagnosis within 2-4 weeks preceding delivery, bridging with intravenous UFH should be considered during labour, to limit the length of time without anticoagulation [16, 39]. Placement of neuraxial anesthesia is safe 4 hours after IV UFH is stopped, when aPTT normalizes; 12 hours following a prophylactic dose of $\mathrm{LMWH}$; or 24 hours after a therapeutic dose of LMWH [56].

Re-initiation of LMWH can typically be accomplished safely 4-6 hours after vaginal delivery or 6-12 hours after Caesarean section, but at least 4 hours after removal of the epidural catheter $[21,56]$. Respecting these time-frames, one approach is to give a prophylactic dose of LMWH once hemostasis is satisfactory, followed by resumption of the therapeutic dose 24 hours later, as indicated [16].

All women with BMI $40 \mathrm{~kg} / \mathrm{m}^{2}$ or greater should be considered for prophylactic dose of $\mathrm{LMWH}$ in weight-adjusted doses for 10 days after delivery, regardless of mode of delivery (vaginal, elective or emergency Caesarean section) [6]. When $\mathrm{BMI}=30 \mathrm{~kg} / \mathrm{m}^{2}$ or more, but less than $40 \mathrm{~kg} / \mathrm{m}^{2}$, additional risk factors must be taken into consideration (Table 1) when deciding on postpartum thromboprophylaxis. Anticoagulation in the setting of an acute VTE diagnosed in pregnancy should continue for the duration of pregnancy and for at least 6 weeks postpartum; for a total duration of at least three months $[12,19,29]$. LMWH and warfarin can be used in the postpartum period, as both are compatible with breastfeeding $[12,19,29]$.

\section{REFERENCES}

1. Marik PE, Plante LA. Venous thromboembolic disease and pregnancy. N Engl J Med. 2008; 359(19): 2025-2033, doi: 10.1056/NEJMra0707993, indexed in Pubmed: 18987370.

2. Surveillance of maternal deaths in the UK 2012-14 and lessons learned to inform maternity care from the UK and Ireland Confidential Enquiries into Maternal Deaths and Morbidity 2009-14. The MBBRACE-UK Report.

3. Kevane B, Donnelly J, D'Alton M, et al. Risk factors for pregnancy-associated venous thromboembolism: a review. J Perinat Med. 2014; 42(4): 417-425, doi: 10.1515/jpm-2013-0207, indexed in Pubmed: 24334422.

4. Rodger M. Pregnancy and venous thromboembolism: 'TIPPS' for risk stratification. Hematology Am Soc Hematol Educ Program. 2014; 2014(1): 387-392, doi: 10.1182/asheducation-2014.1.387, indexed in Pubmed: 25696883

5. Benedetto C, Marozio L, Tavella AM, et al. Coagulation disorders in pregnancy: acquired and inherited thrombophilias. Ann N Y Acad Sci. 2010; 1205: 106-117, doi: 10.1111/j.1749-6632.2010.05674.x, indexed in Pubmed: 20840261

6. Liston F, Davies GAL. Thromboembolism in the obese pregnant woman. Semin Perinatol. 2011; 35(6): 330-334, doi: 10.1053/j.semperi.2011.05.017, indexed in Pubmed: 22108082

7. Galambosi PJ, Gissler M, Kaaja RJ, et al. Incidence and risk factors of venous thromboembolism during postpartum period: a population- 
-based cohort-study. Acta Obstet Gynecol Scand. 2017; 96(7): 852-861, doi: 10.1111/aogs.13137, indexed in Pubmed: 28369660.

8. Parunov LA, Soshitova NP, Ovanesov MV, et al. Epidemiology of venous thromboembolism (VTE) associated with pregnancy. Birth Defects Res C Embryo Today. 2015; 105(3): 167-184, doi: 10.1002/bdrc.21105, indexed in Pubmed: 26406886.

9. Blanco-Molina A, Trujillo-Santos J, Criado J, et al. RIETE Investigators. Venous thromboembolism during pregnancy or postpartum: findings from the RIETE Registry. Thromb Haemost. 2007; 97(2): 186-190, indexed in Pubmed: 17264945.

10. Royal College of Obstetricians and Gynaecologists. Reducing the risk of thrombosis and embolism during pregnancy and the puerperium. Green-top Guideline No 37a; 2015:1-40.

11. Larsen TB, Sørensen HT, Gislum M, et al. Maternal smoking, obesity, and risk of venous thromboembolism during pregnancy and the puerperium: a population-based nested case-control study. Thromb Res. 2007; 120(4): 505-509, doi: 10.1016/j.thromres.2006.12.003, indexed in Pubmed: 17257657.

12. Share of overweight population by sex and age 2014, Overweight and obesity - BMI statistics. European Health Interview Survey, Eurostat, European Commission 2014

13. Esmon CT. Basic mechanisms and pathogenesis of venous thrombosis. Blood Rev. 2009; 23(5): 225-229, doi: 10.1016/j.blre.2009.07.002, indexed in Pubmed: 19683659.

14. Bourjeily $G$, Paidas $M$, Khalil $H$, et al. Pulmonary embolism in pregnancy. Lancet. 2010; 375(9713): 500-512, doi: 10.1016/S0140-6736(09)60996-X, indexed in Pubmed: 19889451.

15. Allman-Farinelli MA. Obesity and venous thrombosis: a review. Semin Thromb Hemost. 2011; 37(8): 903-907, doi: 10.1055/s-0031-1297369, indexed in Pubmed: 22198855.

16. Chan WS, Rey E, Kent NE, et al. VTE in Pregnancy Guideline Working Group, Society of Obstetricians and Gynecologists of Canada. Venous thromboembolism and antithrombotic therapy in pregnancy. J Obstet Gynaecol Can. 2014; 36(6): 527-553, indexed in Pubmed: 24927193.

17. James $A H$, Jamison MG, Brancazio LR, et al. Venous thromboembolism during pregnancy and the postpartum period: incidence, risk factors, and mortality. Am J Obstet Gynecol. 2006; 194(5): 1311-1315, doi: 10.1016/j.ajog.2005.11.008, indexed in Pubmed: 16647915.

18. Després JP, Lemieux I. Abdominal obesity and metabolic syndrome. Nature. 2006; 444(7121): 881-887, doi: 10.1038/nature05488.

19. Braekkan SK, Siegerink B, Lijfering WM, et al. Role of obesity in the etiology of deep vein thrombosis and pulmonary embolism: current epidemiological insights. Semin Thromb Hemost. 2013; 39(5): 533-540, doi: 10.1055/s-0033-1343355, indexed in Pubmed: 23625755.

20. Darvall KAL, Sam RC, Silverman SH, et al. Obesity and thrombosis. Eur J Vasc Endovasc Surg. 2007; 33(2): 223-233, doi: 10.1016/j. ejvs.2006.10.006, indexed in Pubmed: 17185009.

21. James A. Committee on Practice Bulletins - Obstetrics. Practice bulletin no. 123: Thromboembolism in pregnancy. Obstet Gynecol. 2011; 118(3): 718-729, doi: 10.1097/AOG.0b013e3182310c4c, indexed in Pubmed: 21860313.

22. Drife J. Deep venous thrombosis and pulmonary embolism in obese women. Best Pract Res Clin Obstet Gynaecol. 2015; 29(3): 365-376, doi: 10.1016/j.bpobgyn.2014.08.012, indexed in Pubmed: 25457857.

23. Marik PE, Plante LA. Venous thromboembolic disease and pregnancy. N Engl J Med. 2008; 359(19): 2025-2033, doi: 10.1056/NEJMra0707993, indexed in Pubmed: 18987370.

24. Smith SB, Geske JB, MorgenthalerTI. Risk factors associated with delayed diagnosis of acute pulmonary embolism. J Emerg Med. 2012; 42(1): 1-6, doi: 10.1016/j.jemermed.2011.06.004, indexed in Pubmed: 21958453.

25. Dresang LT, Fontaine $P$, Leeman $L$, et al. Venous thromboembolism during pregnancy. Am Fam Physician. 2008; 77(12): 1709-1716, indexed in Pubmed: 18619081.

26. Drife J. Thromboembolism. Br Med Bull. 2003; 67(1): 177-190, doi: $10.1093 / \mathrm{bmb} / \mathrm{ldg} 010$.

27. Rodger M. Evidence base for the management of venous thromboembolism in pregnancy. Hematology Am Soc Hematol Educ Program. 2010; 2010: 173-180, doi: 10.1182/asheducation-2010.1.173, indexed in Pubmed: 21239789.

28. Goldhaber S, Visani L, Rosa MDe. Acute pulmonary embolism: clinical outcomes in the International Cooperative Pulmonary Embolism Registry (ICOPER). The Lancet. 1999; 353(9162): 1386-1389, doi: 10.1016/s0140-6736(98)07534-5.
29. Le Gal G, Kercret G, Ben Yahmed K, et al. EDVIGE Study Group. Diagnostic value of single complete compression ultrasonography in pregnant and postpartum women with suspected deep vein thrombosis: prospective study. BMJ. 2012; 344: e2635, indexed in Pubmed: 22531869.

30. Chan WS, Spencer FA, Ginsberg JS. Anatomic distribution of deep vein thrombosis in pregnancy. CMAJ. 2010; 182(7): 657-660, doi: 10.1503/cmaj.091692, indexed in Pubmed: 20351121.

31. Royal College of Obstetricians and Gynaecologists. The acute management of thrombosis and embolism during pregnancy and the puerperium. Green-top Guideline No 37b; 2015.

32. Cook JV, Kyriou J. Radiation from CT and perfusion scanning in pregnancy. BMJ. 2005; 331 (7512): 350, doi: 10.1136/bmj.331.7512.350, indexed in Pubmed: 16081454.

33. Tan M, Huisman MV. The diagnostic management of acute venous thromboembolism during pregnancy: recent advancements and unresolved issues. Thromb Res. 2011; 127(Suppl 3): S13-S16, doi: 10.1016/S00493848(11)70005-6, indexed in Pubmed: 21262431.

34. Zuurbier SM, Arnold M, Middeldorp S, et al. Risk of cerebral venous thrombosis in obese women. JAMA Neurol. 2016; 73(5): 579-584, doi: 10.1001/jamaneurol.2016.0001, indexed in Pubmed: 26974867.

35. Saposnik G, Barinagarrementeria F, Brown RD, et al. American Heart Association Stroke Council and the Council on Epidemiology and Prevention. Diagnosis and management of cerebral venous thrombosis: a statement for healthcare professionals from the American Heart Association/American Stroke Association. Stroke. 2011; 42(4): 1158-1192, doi: 10.1161/STR.0b013e31820a8364, indexed in Pubmed: 21293023.

36. Cumurciuc R, Crassard I, Sarov M, et al. Headache as the only neurological sign of cerebral venous thrombosis: a series of 17 cases. J Neurol Neurosurg Psychiatry. 2005; 76(8): 1084-1087, doi: 10.1136/jnnp.2004.056275, indexed in Pubmed: 16024884.

37. Sidhom $Y$, Mansour $M$, Messelmani $M$, et al. Cerebral venous thrombosis: clinical features, risk factors, and long-term outcome in a Tunisian cohort. J Stroke Cerebrovasc Dis. 2014; 23(6): 1291-1295, doi: 10.1016/j.jstrokecerebrovasdis.2013.10.025, indexed in Pubmed: 24462460.

38. Leach JL, Fortuna RB, Jones BV, et al. Imaging of cerebral venous thrombosis: current techniques, spectrum of findings, and diagnostic pitfalls. Radiographics. 2006; 26(Suppl 1): S19-41; discussion S42, doi: 10.1148/rg.26si055174, indexed in Pubmed: 17050515.

39. Bates SM, Greer IA, Middeldorp S, et al.VTE, thrombophilia, antithrombotic therapy, and pregnancy: Antithrombotic Therapy and Prevention of Thrombosis, 9th ed: American College of Chest Physicians Evidence-Based Clinical Practice Guidelines. Chest. 2012; 141(2 Suppl): e691S-e736S, doi: 10.1378/chest.11-2300, indexed in Pubmed: 22315276.

40. Harenberg J, Schneider D, Heilmann L, et al. Lack of anti-factor Xa activity in umbilical cord vein samples after subcutaneous administration of heparin or low molecular mass heparin in pregnant women. Haemostasis. 1993; 23(6): 314-320, indexed in Pubmed: 8034237.

41. Flessa HC, Kapstrom AB, Glueck HI, et al. Placental transport of heparin. Am J Obstet Gynecol. 1965; 93(4): 570-573, indexed in Pubmed: 5891551.

42. Greer IA, Nelson-Piercy C. Low-molecular-weight heparins for thromboprophylaxis and treatment of venous thromboembolism in pregnancy: a systematic review of safety and efficacy. Blood. 2005; 106(2): 401-407, doi: 10.1182/blood-2005-02-0626, indexed in Pubmed: 15811953.

43. Sanson BJ, Lensing AW, Prins MH, et al. Safety of low-molecular-weight heparin in pregnancy: a systematic review. Thromb Haemost. 1999; 81(5): 668-672, indexed in Pubmed: 10365733.

44. Pettilä V, Leinonen $\mathrm{P}$, Markkola A, et al. Postpartum bone mineral density in women treated for thromboprophylaxis with unfractionated heparin or LMW heparin. Thromb Haemost. 2002; 87(2): 182-186, indexed in Pubmed: 11858475.

45. Schindewolf M, Mosch G, Bauersachs RM, et al. Safe anticoagulation with danaparoid in pregnancy and lactation. Thromb Haemost. 2004; 92(1): 211, indexed in Pubmed: 15213864

46. Mazzolai L, Hohlfeld P, Spertini F, et al. Fondaparinux is a safe alternative in case of heparin intolerance during pregnancy. Blood. 2006; 108(5): 15691570, doi: 10.1182/blood-2006-03-009548, indexed in Pubmed: 16645165.

47. Blickstein D, Blickstein I. The risk of fetal loss associated with Warfarin anticoagulation. Int J Gynaecol Obstet. 2002; 78(3): 221-225, indexed in Pubmed: 12384267.

48. Della Corte A, De Feo M, Romano G, et al. Risk of warfarin anticoagulation in pregnant patients with mechanical heart valve prostheses. J Heart Valve Dis. 2004; 13(Suppl 1): S90, indexed in Pubmed: 15225015. 
49. Walfisch A, Koren G. The "warfarin window" in pregnancy: the importance of half-life. J Obstet Gynaecol Can. 2010; 32(10): 988-989, doi: 10.1016/s1701-2163(16)34689-8.

50. Turrentine MA, Braems G, Ramirez MM. Use of thrombolytics for the treatment of thromboembolic disease during pregnancy. Obstet Gynecol Surv. 1995; 50(7): 534-541, doi: 10.1097/00006254-199507000-00020, indexed in Pubmed: 7566831.

51. Leonhardt G, Gaul C, Nietsch HH, et al. Thrombolytic therapy in pregnancy. J Thromb Thrombolysis. 2006; 21(3): 271-276, doi: 10.1007/s11239006-5709-z, indexed in Pubmed: 16683220.

52. Kawamata K, Chiba Y, Tanaka R, et al. Experience of temporary inferior vena cava filters inserted in the perinatal period to prevent pulmonary embolism in pregnant women with deep vein thrombosis. J Vasc Surg. 2005; 41(4): 652-656, doi: 10.1016/j.jvs.2005.01.023, indexed in Pubmed: 15874930.

53. Decousus $H$, Leizorovicz A, Parent $F$, et al. A clinical trial of vena caval filters in the prevention of pulmonary embolism in patients with proxi- mal deep-vein thrombosis. Prévention du Risque d'Embolie Pulmonaire par Interruption Cave Study Group. N Engl J Med. 1998; 338(7): 409-415, doi: 10.1056/NEJM199802123380701, indexed in Pubmed: 9459643.

54. Miyahara T, Miyata T, Shigematsu K, et al. Clinical outcome and complications of temporary inferior vena cava filter placement. J Vasc Surg. 2006; 44(3): 620-624, doi: 10.1016/j.jvs.2006.05.019, indexed in Pubmed: 16950444.

55. Patel JP, Green B, Patel RK, et al. Population pharmacokinetics of enoxaparin during the antenatal period. Circulation. 2013; 128(13): 1462-1469, doi: 10.1161/CIRCULATIONAHA.113.003198, indexed in Pubmed: 23940396.

56. Horlocker T, Wedel D, Rowlingson J, et al. Regional anesthesia in the patient receiving antithrombotic or thrombolytic therapy: American Society of Regional Anesthesia and Pain Medicine Evidence-Based Guidelines (Third Edition). Reg Anesth Pain Med. 2010; 35(1): 64-101, doi: 10.1097/aap.0b013e3181c15c70. 